\title{
UTILIZAÇÃO DE MODELOS FÍSICO-QUÍMICOS DE ADSORÇÃO NO ESTUDO DO COMPORTAMENTO DO COBRE EM SOLOS ARGILOSOS
}

Fernando Fabriz Sodré e Ervim Lenzi

Departamento de Química, Universidade Estadual de Maringá, Av. Colombo, 5790, 87020-900 Maringá - PR

Antonio Carlos Saraiva da Costa

Departamento de Agronomia, Universidade Estadual de Maringá

Recebido em 19/5/00; aceito em 4/10/00

\begin{abstract}
APPLICABILITY OF ADSORPTION MODELS TO THE STUDY OF COPPER BEHAVIOUR IN CLAYEY SOILS. It was evaluated the applicability of Langmuir, Freundlich and Temkin models to copper adsorption in three classes of soils. Fractions of each soil were added to test tubes containing growing concentrations of the metal in solution. The tubes were shaken and the copper concentrations were determined in the extracts by atomic absorption spectrometry (AAS). The models offered a good fit for the experimental data indicating that presence of silicated clay had high influence on copper sorption. The Langmuir isotherm showed high influence of the organic matter in the absorption phenomenon. It was evidenced the importance of further studies related to Temkin model.
\end{abstract}

Keywords: adsorption isotherms; heavy metal; tropical soils.

\section{INTRODUÇÃO}

Varios estudos ambientais indicam que o homem tornou-se o mais importante fator no ciclo biogeoquímico de metais pesados. A mobilização destes poluentes para a biosfera tem alcançado níveis preocupantes ${ }^{1}$. O solo é um componente muito específico da biosfera, pois além de ser um depósito geoquímico de metais contaminantes, controla também o transporte destas substâncias para a atmosfera, a hidrosfera e a biota. A presença destes contaminantes no ambiente possibilita a bioacumulação e a biomagnificação na cadeia alimentar, proporcionando distúrbios nos processos metabólicos dos seres vivos. A bioacumulação e a biomagnificação encarregam-se de transformar concentrações normais em concentrações tóxicas para diferentes espécies da biota e para o próprio homem ${ }^{2}$. Deste modo, a poluição do solo por metais pesados tem sido reconhecida como um importante problema ambiental, podendo ocasionar riscos ainda desconhecidos para a saúde de gerações futuras ${ }^{3}$.

O cobre, além de ser um metal pesado ${ }^{4}$, atende aos critérios de essencialidade para plantas e microrganismos, sendo classificado como micronutriente. A literatura ${ }^{5}$ descreve a concentração média deste metal no solo como de $20 \mu \mathrm{g} . \mathrm{g}^{-1}$ com variações na faixa de 6 a $80 \mu \mathrm{g} \cdot \mathrm{g}^{-1}$, porém, pode ser acrescido ao meio por resíduos urbanos e industriais, pesticidas e fertilizantes, entre outros ${ }^{2}$. Em grandes concentrações, pode proporcionar efeitos tóxicos ao tecido vegetal e causar a deficiência de outros nutrientes essenciais através de interações antagônicas ${ }^{6}$.

A dinâmica do cobre no solo é bastante complexa e altamente afetada por inúmeros fatores do meio, principalmente a composição química, física e mineralógica do solo, a quantidade de matéria orgânica e o $\mathrm{pH}^{7}$. Para uma melhor compreensão dos fatores que controlam o comportamento deste metal no solo, faz-se presente um breve comentário a respeito das características químicas e mineralógicas do meio em questão.

$O$ solo pode ser definido como uma mistura de materiais inorgânicos e orgânicos, formados a partir de uma série de processos operantes na superfície terrestre que ocasionam a decomposição de rochas e minerais primários, graças à ação de agentes atmosféricos, físicos, químicos e biológicos. Este conjunto de processos é denominado intemperismo ${ }^{8}$. Em um solo são encontradas três fases fundamentais: a sólida (formada por minerais e pela matéria orgânica), a líquida (solução do solo) e a gasosa (ar do solo). Os minerais da fase sólida são classificados de acordo com o diâmetro de suas partículas em: areia, silte e argila. Segundo Atkins ${ }^{9}$, um colóide é um sistema de duas fases onde partículas menores que $5 \mu \mathrm{m}$ encontram-se dispersas em outra substância. Deste modo, os colóides do solo são formados pela interface existente entre a solução do solo e os constituintes da fase sólida do mesmo. Os principais componentes da fração dispersa coloidal dos solo são os materiais orgânicos e os minerais secundários da fração argila (argilominerais expansivos e oxo-hidróxidos de ferro e alumínio). Os minerais da fração silte menores que $5 \mu \mathrm{m}$ também compõem a interface coloidal do sistema, mas pouco influem nos fenômenos adsortivos do solo.

Dependendo da natureza do colóide, os grupos funcionais em suas superfícies determinam uma maior ou menor adsorção do metal. Na matéria orgânica do solo, estes grupos são, principalmente, unidades funcionais carboxílicas e fenólicas que, geralmente, formam estruturas negativamente carregadas ${ }^{10}$. A complexação do cobre pela matéria orgânica do solo é a mais forte entre os metais de transição divalentes ${ }^{5}$. Nos óxidos e hidróxidos de ferro e alumínio, e nas periferias das argilas silicatadas (argilominerais expansivos), os grupos funcionais de superfície são originados pela dissociação de grupamentos hidroxila. Nestes sítios, a adsorção do cobre pode ocorrer por meio da formação de ligações covalentes ou eletrostáticas ${ }^{11}$. Este fenômeno é muito importante em solos tropicais, onde a elevada quantidade de oxo-hidróxidos determina uma grande capacidade de retenção do metal ${ }^{5}$. Nos argilominerais expansivos (argilas 2:1), os grupos funcionais podem ocorrer nos espaços entre as camadas octaédricas presentes em suas estruturas cristalinas. Neste caso, acredita-se que o cobre seja fortemente adsorvido, formando complexos de esfera interna ${ }^{12}$.

Outro fator decisivo na dinâmica do cobre é a capacidade de troca catiônica (CTC) de um solo. A CTC está intimamente ligada as concentrações dos íons trocáveis presentes na solução do solo e aos sítios de troca nas interfaces coloidais do sistema. Uma elevada CTC proporciona uma maior retenção do metal no solo ${ }^{13}$. A matéria orgânica, embora represente, em média, como cerca de $5 \%$ dos componentes sólidos, é responsável por cerca de $30 \%$ a $65 \%$ da CTC dos solos minerais, e mais de $50 \%$ da CTC de solos arenosos e orgânicos ${ }^{14}$. 
$\mathrm{O}$ pH exerce também uma forte influência na dinâmica do cobre no solo ${ }^{15,16}$. Ambientes ácidos determinam uma maior mobilidade do metal, enquanto condições de $\mathrm{pH}$ acima de seis favorecem a sua retenção, principalmente em solos com elevado grau de intemperização, onde os grupos funcionais de superfície dos componentes coloidais são, na sua maioria, $\mathrm{pH}-$ dependentes (oxo-hidróxidos de ferro e alumínio).

O cobre ocorre nos sólidos e na solução do solo quase que exclusivamente na forma de $\mathrm{Cu}$ (II). As formas reduzidas monovalente e metálica, são possíveis somente em solos sob condições de redução, especialmente na presença de íons de enxofre e halogênios 5 .

Uma boa maneira de estudar o comportamento de um metal no solo é aplicando modelos físico-químicos de adsorção. De um modo geral, a relação entre a quantidade de um metal adsorvido pela fase sólida do solo $(\theta)$ e a concentração do mesmo na solução do solo $(C)$, é quantificada através de uma isoterma (relação $\theta / C$ ) que permite conhecer mais a respeito da natureza dos processos de adsorção. Os três modelos de adsorção freqüentemente adotados para solos são os de Langmuir, Freundlich e Temkin. A teoria de Langmuir baseiase no fato da adsorção ocorrer em sítios uniformes com recobrimento em monocamada e afinidade iônica independente da quantidade de material adsorvido. Em soluções iônicas sua validade de uso prende-se mais ao fato de constituir uma boa equação empírica, do que atender as condições físicas pré-determinadas ${ }^{17}$. $\mathrm{O}$ modelo de Freundlich considera a não uniformidade das superfícies reais e, quando aplicado ao solo, descreve bem a adsorção iônica dentro de certos limites de concentração, mas acima deles apresenta dificuldades em considerar a quantidade de íons presentes no solo ${ }^{18}$. A teoria de Temkin considera que há diferenciação na estabilidade dos centros de absorção e que os sítios mais energéticos são primeiramente ocupados pelos íons em solução, sendo que a afinidade iônica tende a decrescer linearmente com o aumento da adsorção 9 . Este trabalho objetivou estudar a aplicabilidade destes modelos na adsorção de cobre em três solos argilosos com diferentes mineralogias.

\section{MATERIAL E MÉTODOS}

Foram utilizados solos derivados do basalto ${ }^{19}$ presentes em uma toposeqüência de solos na região metropolitana de Maringá: um Latossolo Roxo (LR), um Solo Litólico (R) e um Vertissolo (V). Amostras de aproximadamente $2 \mathrm{~kg}$ de cada tipo de solo foram coletadas na camada superficial $(0-20$ $\mathrm{cm}$ ), secadas ao ar em casa de vegetação e peneiradas em peneira de polietileno com malha de $2 \mathrm{~mm}$ de diâmetro. A partir deste material foram realizadas análises físicas, químicas e mineralógicas dos solos.

\section{Análises físicas e químicas}

Textura. A análise granulométrica por dispersão total foi realizada segundo o método da pipeta descrito em Embrapa ${ }^{20}$. Este método baseia-se na velocidade de queda das partículas que compõe o solo após a adição de um dispersante químico ( $\left.\mathrm{NaOH} 1 \mathrm{~mol} . \mathrm{L}^{-1}\right)$.

Área superficial específica total (ASE). Para esta determinação, utilizou-se o método indireto de adsorção do etilenoglicol monoetil éter (EMGE) ${ }^{21}$.

Determinação do carbono orgânico. Com o auxílio de um "cachimbo volumétrico" (tubo de vidro de $1 \mathrm{~mL}$ de capacidade fixado na ponta de uma haste de vidro para manipular o mesmo), transferiu-se 1,0 mL de solo para erlenmeyer de $250 \mathrm{~mL}$ de capacidade. Adicionaram-se $10 \mathrm{~mL}$ de solução $\mathrm{K}_{2} \mathrm{Cr}_{2} \mathrm{O}_{7}$ 0,5 mol. $\mathrm{L}^{-1}$ e $20 \mathrm{~mL}$ de $\mathrm{H}_{2} \mathrm{SO}_{4}$ concentrado. Agitou-se a mistura manualmente e deixou-se em repouso por 30 minutos.
A seguir, adicionaram-se $100 \mathrm{~mL}$ de água deionizada, $10 \mathrm{~mL}$ de $\mathrm{H}_{3} \mathrm{PO}_{4}$ concentrado e 6 gotas de solução de difenilamina a $1 \%$ em ácido sulfúrico concentrado. Titulou-se com solução de sulfato ferroso amoniacal $0,5 \mathrm{~mol} . \mathrm{L}^{-1}$ até que a coloração da solução passasse de azul escuro para verde, considerando-se aí o ponto final da titulação. A partir do volume gasto calculouse o teor de $\mathrm{C}$ orgânico da amostra do solo ${ }^{20}$.

pH em água. Transferiram-se $10,0 \mathrm{~mL}$ de solo e $25 \mathrm{~mL}$ de água deionizada para um erlenmeyer de $50 \mathrm{~mL}$ de capacidade. Agitou-se a mistura durante 5 minutos e deixou-se em repouso por mais 20 minutos. Fez-se a determinação do $\mathrm{pH}$ na suspensão ${ }^{20}$

pH em $\mathrm{CaCl}_{2}$. Transferiram-se $10,0 \mathrm{~mL}$ de solo e $25 \mathrm{~mL}$ de solução de $\mathrm{CaCl}_{2} \quad 0,01 \mathrm{~mol} . \mathrm{L}^{-1}$ para um erlenmeyer de $50 \mathrm{~mL}$ de capacidade. Agitou-se a mistura durante 15 minutos e deixou-se em repouso por mais 30 minutos. Fez-se a determinação do $\mathrm{pH}$ na suspensão ${ }^{20,22}$.

Acidez trocável $\left(H^{+}+A l^{3+}\right)$. Ao material utilizado para a determinação do $\mathrm{pH}$ em $\mathrm{CaCl}_{2}$, adicionaram-se $5 \mathrm{~mL}$ de solução tampão SMP (Shoemaker, McLean e Pratt) ${ }^{22}$. Agitou-se durante 20 minutos e deixou-se em repouso por mais 60 minutos. Em seguida, agitou-se novamente por mais 10 minutos e deixou-se em repouso por 60 minutos. Fez-se a determinação do $\mathrm{pH}$ na suspensão. Os dados obtidos foram convertidos para acidez trocável através de valores tabelados ${ }^{23}$.

Determinação de cálcio, magnésio e alumínio. Para fazer a troca destes metais do solo para a solução transferiram-se 5,0 $\mathrm{mL}$ de solo e $50 \mathrm{~mL}$ de solução $\mathrm{KCl}$ 1,0 mol. $\mathrm{L}^{-1}$ para erlenmeyer de $125 \mathrm{~mL}$ de capacidade. Agitou-se a mistura por 15 minutos e deixou-se em repouso por uma noite.

Para a determinação da concentração do magnésio, transferiu-se 1,0 $\mathrm{mL}$ do sobrenadante em recipiente apropriado e adicionaram-se $25 \mathrm{~mL}$ de água deionizada e $1,5 \mathrm{~mL}$ de solução de lantânio a $100 \mathrm{mg} \cdot \mathrm{L}^{-1}$. Para a determinação da concentração do cálcio, transferiu-se $1,0 \mathrm{~mL}$ do sobrenadante em recipiente apropriado e adicionaram-se $25 \mathrm{~mL}$ de água deionizada e 2 $\mathrm{mL}$ de solução $\mathrm{KCl} 1,3 \mathrm{~mol} \cdot \mathrm{L}^{-1}$. Fez-se a determinação dos dois elementos por espectrometria de absorção atômica, em chama ar-acetileno, no espectrômetro de absorção atômica SpectrAA 10 Plus da VARIAN. Quanto ao alumínio, fez-se a determinação no sobrenadante por espectrometria de absorção atômica, chama óxido nitroso-acetileno ${ }^{22,23}$.

Determinação de metais $(K, \mathrm{Cu}, \mathrm{Fe}$, etc) através de solução extratora Mehlich 1 (solução extratora duplo-ácida). Transferiram-se 5,0 mL de solo para erlenmeyer de $125 \mathrm{~mL}$ de capacidade e adicionaram-se $50 \mathrm{~mL}$ da solução Mehlich 1 ( $\mathrm{HCl} 0,05$ mol.L$\left.{ }_{1} \mathrm{e}_{2} \mathrm{SO}_{4} 0,0125 \mathrm{~mol} . \mathrm{L}^{-1}\right)$. Agitou-se por 5 minutos e, em seguida, filtrou-se o material em suspensão. As concentrações de cobre e potássio foram determinadas no filtrado por espectrometria de absorção atômica, modalidade chama ar-acetileno ${ }^{22,23}$.

Capacidade de troca catiônica (CTC). A CTC do solo foi calculada pela soma dos cátions trocáveis $\left(\mathrm{Ca}^{2+}, \mathrm{Mg}^{2+}\right.$ e $\left.\mathrm{K}^{+}\right)$ com a acidez trocável $\left(\mathrm{H}^{+}+\mathrm{Al}^{3+}\right)^{22,23}$.

\section{Análises mineralógicas}

A análise de raios-x deu-se em ângulo de $2 \theta$, de 2 a $35^{\circ}$ para as frações argila dos solos tratadas com DCB (ditionitocitrato bicarbonato $)^{24}$ e de 15 a $65^{\circ}$ para as argilas tratadas com $\mathrm{NaOH} 5$ mol. $\mathrm{L}^{-1}$ fervente ou a quente $\left(\sim 100^{\circ} \mathrm{C}\right)^{25}$, utilizando a radiação $\mathrm{K} \alpha$ (do elemento cobre) de um difratômetro de raios-x Philips PW 1316/90. A quantificação da caulinita e da gibbsita foi obtida por análise termogravimétrica ${ }^{26}$, em equipamento Seiko 200 com termopar de Pt-Pt Rh (13\%) controlado por uma estação Seiko SSC - 5020, capaz de determinar simultaneamente por termogravimetria (TG) e por análise térmica diferencial (DTA). 


\section{Adsorção do cobre nos solos}

A fração seca ao ar dos solos foi moída manualmente em gral de porcelana e peneirada em peneira metálica com malha de $0,074 \mathrm{~mm}$ de diâmetro para homogeneizar o tamanho das partículas dos solos e eliminar possíveis diferenças de sorção causadas por variações dimensionais nos agregados dos solos ${ }^{27}$. Frações de 1,00 g de cada solo, em triplicata, foram pesadas e transferidas a tubos de ensaio contendo $7,0 \mathrm{~mL}$ da solução matriz de $\mathrm{CaCl}_{2} \cdot 2 \mathrm{H}_{2} \mathrm{O} 0,002 \mathrm{~mol} . \mathrm{L}^{-1}$, enriquecida com 0 , 5 , $10,20,40,60,80$, e $100 \mu \mathrm{g} \cdot \mathrm{mL}^{-1}$ de cobre na forma de $\mathrm{CuCl}_{2} \cdot 2 \mathrm{H}_{2} \mathrm{O}$, respectivamente. Os tubos foram submetidos à agitação durante 4 horas em agitador horizontal, permanecendo, em seguida, sob repouso por mais 20 horas. A seguir, foram centrifugados por 2 horas a $2000 \mathrm{rpm}$. Neste período de contato, as reações de sorção alcançam, virtualmente, o equilíbrio $^{28}$. Fez-se a análise dos tratamentos no $\mathrm{pH}$ de 5,8 da solução matriz de $\mathrm{CaCl}_{2} \cdot 2 \mathrm{H}_{2} \mathrm{O}$, à temperatura ambiente.

A concentração de cobre foi determinada nos extratos utilizando-se o espectrômetro de absorção atômica Varian Spectra AA 10 Plus, modalidade chama com a mistura ar-acetileno. A quantidade de cobre adsorvido $(\theta)$ foi calculada subtraindo-se da concentração do metal inicialmente adicionada, a concentração de equilíbrio $(C)$ determinada nos extratos ${ }^{12}$. A partir destes dados foram construídas isotermas segundo as relações lineares dos modelos de adsorção.

\section{Linearização das equações de adsorção}

A equação de Langmuir é a seguinte:

$$
\theta=K b C /(1+K C)
$$

onde $K$ indica a energia de ligação e $b$ é a capacidade máxima de adsorção do íon no solo (CMAI). Invertendo os termos da equação, temos

$$
1 / \theta=1 / K b C+1 / b
$$

Multiplicando a equação (2) por $C$, tem-se a forma linearizada para a equação de Langmuir

$$
C / \theta=1 / K b+C / b
$$

Considerando $C / \theta$ como variável dependente e $C$ como variável independente, obtêm-se os valores de $K$ e $b$, onde $1 /$ $K b$ é o coeficiente linear e $1 / b$ é o coeficiente angular da reta.

A equação de Freundlich é a seguinte:

$\theta=k f C^{1 / n}$

onde $n$ indica, qualitativamente, a reatividade dos sítios energéticos do solo ${ }^{12}$ e $k f$ pode sugerir a adsorção do íon no solo.

Aplicando propriedades logarítmicas temos

$\log \theta=\log k f+1 / n \log C$

Fazendo-se o gráfico de $\log \theta$ versus $\log C$, obtêm-se os valores de $k f$ e $n$, onde $\log k f$ é o coeficiente linear e $1 / n$ é o coeficiente angular da reta.

A equação de Temkin é a seguinte:

$\theta=A \ln C+B$

onde $A$ e $B$ são parâmetros da equação. Fazendo-se o gráfico de $\theta$ versus $\ln C$, obtêm-se os valores de $A$ e $B$, onde $B$ é o coeficiente linear e $A$ é o coeficiente angular da reta.

Os coeficientes obtidos a partir destas equações foram utilizados para ajustar os modelos teóricos aos dados obtidos experimentalmente.

\section{RESULTADOS E DISCUSSÃO}

O grau de intemperismo e a ação de processos específicos de formação determinaram variações significativas nas características dos solos ao longo da toposeqüência de solos, onde o desenvolvimento dos mesmos é fortemente influenciado pela topografia local.

Os solos $\mathrm{R}$ e $\mathrm{V}$, apresentam maiores teores de bases trocáveis (Tabela 1) e menores conteúdos de hidrogênio e alumínio, que se concentram no sistema conforme o avanço da atividade intempérica e refletem a intensidade da mesma. Entre os solos mais jovens, observa-se que o solo $\mathrm{V}$ é o menos intemperizado, apresentando os maiores valores de capacidade de troca catiônica (CTC) e pH (Tabela 1) e a maior área superficial específica total (ASE) entre os solos (Tabela 2). O teor de cobre, extraído por solução duplo-ácida de Mehlich 1, foi maior nos solos mais jovens. No caso do ferro, o mesmo não pode ser observado devido às condições redox do solo $\mathrm{V}$, que determinou a remoção do mesmo do sistema (Tabela 1).

Tabela 1. Características químicas dos solos estudados.

\begin{tabular}{ccccccccccc}
\hline Solos $^{(1)}$ & $\mathrm{pH}$ & $\mathrm{MO}^{(2)}$ & $\mathrm{Al}^{3+}$ & $\mathrm{H}^{+}+\mathrm{Al}^{3+}$ & $\mathrm{Ca}^{2+}$ & $\mathrm{Mg}^{2+}$ & $\mathrm{K}^{+}$ & $\mathrm{CTC}$ & $\mathrm{Fe}$ & $\mathrm{Cu}$ \\
\hline \multicolumn{7}{c}{$\mathrm{mg} \cdot \mathrm{dm}^{-3}$} \\
\hline LR & 4,7 & 22,8 & 2,2 & 7,80 & 1,07 & 0,74 & 0,38 & 9,99 & 157 & 17,7 \\
R & 6,0 & 36,3 & 0 & 4,77 & 11,60 & 4,50 & 0,87 & 20,74 & 211 & 37,9 \\
V & 6,7 & 20,1 & 0 & 4,05 & 17,49 & 9,80 & 0,27 & 31,61 & 41 & 50,1 \\
\hline
\end{tabular}

(1) LR - Latossolo Roxo, R - Solo Litólico e V - Vertissolo; ${ }^{(2)} \mathrm{MO}$ indica o teor de matéria orgânica: $\mathrm{MO}=(\mathrm{Carbono}$ orgânico(g.dm $\left.\left.{ }^{-3}\right) \times 1,724\right) / 10$.

Tabela 2. Características físicas e mineralógicas dos solos estudados.

\begin{tabular}{ccccccccc}
\hline Solos $^{(1)}$ & ASE $^{(2)}$ & \multicolumn{3}{c}{ Análise granulométrica } & \multicolumn{3}{c}{ Mineralogia da fração argila(a) } \\
\hline & & Areia & Silte & Argila & $\mathrm{Fe}_{2} \mathrm{O}_{3}$ & Gibbsita & Caulinita & Argilas 2:1 \\
\hline & $\mathrm{m}^{2} \cdot \mathrm{g}^{-1}$ & & $\%$ & & & & $\%$ & \\
$\mathrm{LR}$ & 97 & 29 & 11 & 60 & 16 & 6 & 68 & 10 \\
$\mathrm{R}$ & 184 & 29 & 12 & 59 & 14 & 4 & 67 & 15 \\
$\mathrm{~V}$ & 256 & 29 & 13 & 58 & 6 & 0 & 54 & 40 \\
\hline
\end{tabular}

(1)LR - Latossolo Roxo, R - Solo Litólico e V - Vertissolo. ${ }^{(2)}$ ASE - Área Superficial Específica total. ${ }^{(3)} \mathrm{Fe}_{2} \mathrm{O}_{3}-\mathrm{Denominação}$ genérica para óxidos e hidróxidos do metal. Argilas 2:1 ou filossilicatos do tipo 2:1. 
Os solos amostrados apresentam características químicas, físicas e mineralógicas comuns em solos derivados das rochas vulcânicas básicas do Derrame do Trapp ${ }^{29}$. São argilosos, com baixo conteúdo de areia e silte (Tabela 2). Os processos pedogenéticos de formação determinam um gradiente de comportamento entre o Latossolo Roxo (LR) e os solos mais jovens, Solo Litólico (R) e Vertissolo (V).

As análises mineralógicas por difratometria de raios-X (Figura 1) e termogravimetria (Figura 2), indicam que os solos apresentam caulinita como mineral predominante. No solo LR, observam-se teores consideráveis de oxo-hidróxidos de ferro (hematita, goethita e maghemita) e alumínio (gibbsita).

Esses minerais possuem elevado $\mathrm{pH}$ no ponto de carga zero (PCZ) e proporcionam uma elevada capacidade de retenção de metais em solos através de diferentes processos físico-químicos, tais como adsorção, co-precipitação, oclusão, entre outros ${ }^{5,12}$. Nos solos $\mathrm{R}$ e V, pode-se observar concentrações crescentes de minerais expansivos do tipo 2:1 (vermiculitas e, ou esmectitas), e decrescentes de oxo-hidróxidos de ferro e alumínio ${ }^{30}$.

Os elevados coeficientes de correlação obtidos a partir das equações linearizadas de Langmuir, Freundlich e Temkin (Tabela 3), indicam que os três modelos de adsorção apresentaram-se significativamente capazes em detectar a adsorção de cobre nos solos estudados.

O modelo de adsorção de Langmuir tem sido largamente utilizado para estimar a capacidade de adsorção de solos para vários elementos e espécies químicas ${ }^{31-35}$. Sua principal vantagem sobre as outras isotermas é permitir quantificar a capaci- dade de adsorção de espécies químicas no solo e avaliar a constante relacionada à energia de ligação.

$\mathrm{O}$ parâmetro $b$ da equação de Langmuir tem sido utilizado para estimar a capacidade máxima de adsorção (CMA) para vários elementos químicos presentes nos solos. Neste estudo, os valores obtidos indicam uma elevada $\mathrm{CMACu}$ para o solo $\mathrm{V}$ (Tabela 3), proporcionada pela grande porcentagem de argilas do tipo 2:1 (Tabela 2).

Em estudos de extração seqüencial, pode-se quantificar e qualificar as formas de retenção de um metal nos diferentes componentes coloidais do solo. Neste tipo de análise, Matos e colaboradores ${ }^{14}$ observaram que aproximadamente $40 \%$ do total de cobre adicionado a um Latossolo Vermelho-Amarelo Húmico, via $\mathrm{CuCl}_{2} \cdot \mathrm{H}_{2} \mathrm{O}$, ficou retido na fração residual (argilas 2:1). Nos solos LR e R, a predominância de minerais de baixa ASE e CTC, como a caulinita e os oxo-hidróxidos de ferro e alumínio $^{12}$ (Tabela 2), determinam que os componentes orgânicos dos solos devem ser os responsáveis por grande parte da $\mathrm{CMACu}$. A matéria orgânica humificada do solo possui uma grande ASE e uma elevada CTC, devido à natureza de seus grupos funcionais de superfície ${ }^{10,36}$. Além disso, a elevada afinidade entre o metal e a matéria orgânica do solo ${ }^{5,10}$ determina a formação de uma isoterma de adsorção do tipo $\mathrm{H}^{12}$, que se caracteriza pela forte adsorção inicial do metal pela superfície do adsorvente ${ }^{31}$. Os parâmetros $k f$ de Freundlich e $B$ de Temkin também podem indicar, empiricamente, a capacidade adsortiva dos solos. Apesar dos valores observados terem-se mostrado distantes da adsorção máxima estimada pela equação de Langmuir (Tabela 3 ), as tendências destes dados apresentam semelhanças.
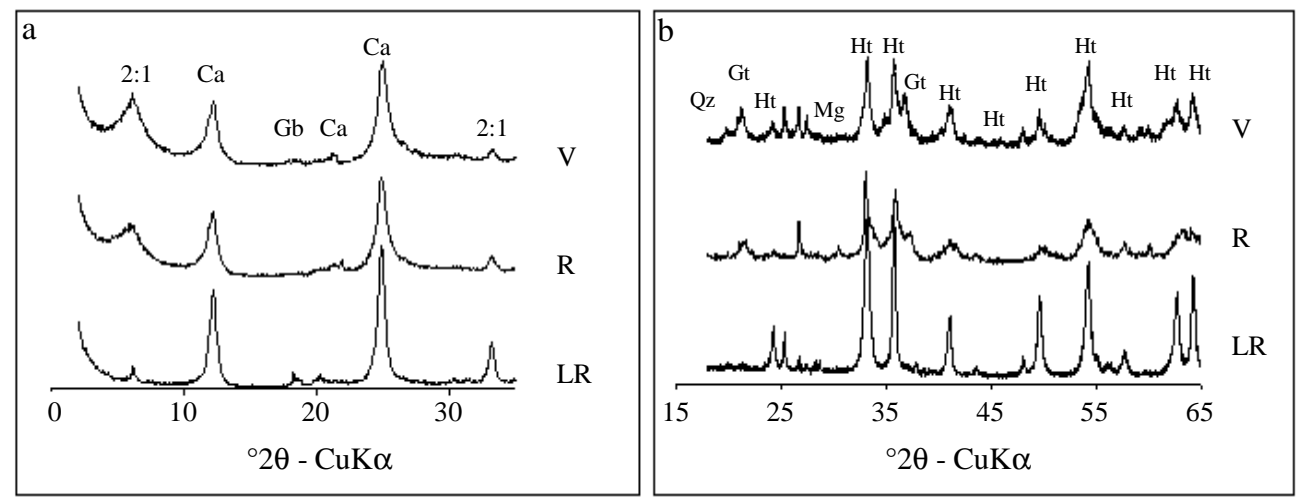

Figura 1. Difratogramas de raios-x da fração argila dos solos amostrados após tratamento com (a) DCB e (b) NaOH 5 mol.L $L^{-1}$ em ebulição. $L R$ - Latossolo Roxo, $R$ - Solo Litólico e V-Vertissolo. Ca - caulinita, Gb - gibbsita, 2:1 - vermiculita e, ou esmectita, Qz - quartzo, Ht hematita; Mg - maghemita, Gt - goethita.

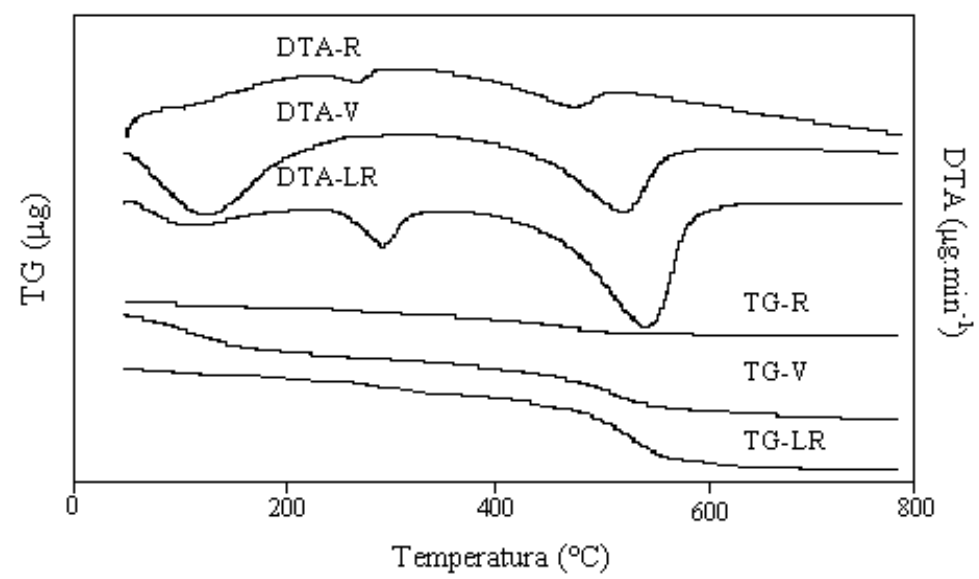

Figura 2. Análise termogravimétrica (TG) e termogravimetria diferencial (DTA) das amostras da fração argila após tratamento com DCB. LR - Latossolo Rocho; V - Vertissolo; R - Solo Litólico. 
Pela análise dos parâmetros relacionados com a energia de ligação ( $K$ de Langmuir), observa-se que o solo $\mathrm{V}$ apresentou elevado valor de $K$ em comparação com os dados obtidos para os outros solos (Tabela 3). Neste caso, acredita-se que o cobre foi fortemente retido através de ligações de caráter covalente na estrutura cristalina das argilas do tipo 2:1. Este fenômeno sugere que o mecanismo de adsorção do cobre pode ser caracterizado por reações de troca catiônica do $\mathrm{H}^{+}$pelo $\mathrm{Cu}^{2+}$, se o sítio estiver protonado, ou, se estiver desprotonado, por ligação dativa entre o par eletrônico do oxigênio e o cobre $\left(\mathrm{M}-\mathrm{O}:^{-} \rightarrow \mathrm{Cu}^{2+}\right)$ nas superfícies laterais destes minerais, lembrando que estas cargas negativas podem originar-se das trocas isomórficas (cargas permanentes) e outras dependentes do $\mathrm{pH}$. Ou seja, este processo de quimiossorção é controlado pela natureza do solo e pela quantidade dos grupamentos hidroxila periféricos. Utilizando técnicas de espectroscopia de ressonância paramagnética eletrônica (EPR) no estudo da adsorção de cobre por oxo-hidróxidos de alumínio cristalinos e amorfos, $\mathrm{McBride}^{37}$ confirmou que o mecanismo que envolve a imobilização do metal caracteriza-se pela formação de pelo menos uma ligação do tipo $\mathrm{Cu}-\mathrm{O}-\mathrm{Al}$. Este tipo de adsorção específica é responsável pela formação de complexos de esfera interna entre o cobre e os minerais do solo ${ }^{12}$.

Segundo Barrow ${ }^{18}$, os parâmetros $n$ e $k f$ de Freundlich não demonstram nenhum significado físico e a isoterma formada por este modelo teórico descreve bem a adsorção dentro de certos valores de concentração, mas acima deles apresenta certas limitações, entre elas, a dificuldade de considerar adequadamente a quantidade de íons presente no solo (parâmetro $k f$ ). Entretanto, Sposito $^{38}$ estudou as derivações da equação de Freundlich para íons trocáveis em solos e observou uma relação qualitativa entre o parâmetro $n$ e a distribuição dos sítios energéticos na fração dispersa dos colóides do solo. Quando $n=1$, todos os sítios energéticos se equivalem e os dados podem ser ajustados ao modelo teórico de Langmuir. Entretanto, quando $n \neq 1$, a distribuição dos sítios energéticos tende a variar com a densidade de adsorção. Os valores de $n$ para os solos estudados apresentaram valores acima de 1 (Tabela 3), indicando a presença de sítios altamente energéticos e sugerindo que estes são os primeiros a serem ocupados pelo cobre ${ }^{39}$. O maior valor de $n$ para o solo LR $(n=1,90)$ pode indicar uma maior heterogeneidade relacionada aos sítios de adsorção em oposição ao solo $\mathrm{V}(n=1,36)$, onde o elevado teor de argilas do tipo 2:1 (Tabela 2) sugere uma maior equivalência entre a natureza dos sítios energéticos do solo. A teoria de Temkin, que pelo seu aspecto empírico baseiase no conceito de adsorção preferencial em sítios de maior energia, pode também sustentar esta hipótese por ter apresentado coeficientes de correlação linear significativos para os solos em estudo (Tabela 3).

A partir dos parâmetros obtidos pelas equações de Langmuir, Freundlich e Temkin (Tabela 3) e, considerando algumas características dos solos estudados (Tabelas 1 e 2), fez-se um estudo de regressão, cujos resultados encontram-se na Tabela 4. Deve-se salientar que o pequeno número de solos utilizados neste estudo não é o ideal para a formulação de um modelo genérico de regressão, mas, mesmo assim, este tipo de análise torna-se muito importante por oferecer um sentido mais prático às observações.

Analisando-se os coeficientes de correlação linear em que os parâmetros das equações de adsorção são variáveis independentes e as características dos solos são as variáveis explicativas (Tabela 4), observa-se que a matéria orgânica não apresentou significância para seus coeficientes. Este relacionamento pode parecer paradoxal, tendo em vista a grande afinidade entre o cobre e os componentes orgânicos dos solos ${ }^{5,10}$.

$\mathrm{Na}$ verdade, estes coeficientes estão indicando que não há uma relação direta de causa versus efeito entre as variáveis em questão, e que existem outras características dos solos que são suficientes para alterar um relacionamento significativo que poderia existir entre a adsorção do cobre e o teor e o tipo de matéria orgânica ${ }^{33}$. Na mesma linha de pensamento, nota-se que o parâmetro $K$, relacionado à energia de ligação, apresentou coeficientes de correlação negativos para os teores de oxohidróxidos de ferro e para a gibbsita. Como foi mostrado anteriormente, este comportamento pode ter sido influenciado por alguma característica do solo que mascarou o conhecido efeito adsortivo destes minerais ${ }^{5,11}$. Todavia, a tendência de maior energia de ligação do cobre (parâmetro $K$ ) em função da porcentagem de argilas do tipo 2:1 foi constatada através do coeficiente altamente significativo $(0,999)$ observado entre tais variáveis. Dentre os parâmetros que se relacionam com a capacidade adsortiva dos solos, apenas o valor de $k f$ de Freundlich mostrou significância com o teor de argilas do tipo 2:1. Os valores de $b$ de Langmuir e $B$ de Temkin não foram significa-

Tabela 3. Parâmetros das equações de Langmuir, Freundlich e Temkin para adsorção de cobre nos solos estudados.

\begin{tabular}{cccccccccc}
\hline Solos $^{(1)}$ & \multicolumn{3}{c}{ Langmuir $^{(2)}$} & & & Freundlich & \multicolumn{2}{c}{ Temkin } \\
\hline & $b$ & $K$ & $\mathrm{r}^{2}$ & $k f$ & $n$ & $\mathrm{r}^{2}$ & $B$ & $A$ & $\mathrm{r}^{2}$ \\
\hline LR & $\mathrm{mg.g}^{-1}$ & ${\mathrm{~L} . \mathrm{mg}^{-1}}^{-1}$ & & & & & & & \\
R & 0,549 & 0,18 & 0,98 & 13 & 1,90 & 0,99 & 18 & 12,68 & 0,96 \\
V & 0,769 & 3,13 & 0,99 & 158 & 1,73 & 0,97 & 78 & 18,77 & 0,98 \\
& 0,917 & 16,83 & 0,94 & 482 & 1,36 & 0,98 & 136 & 23,86 & 0,97 \\
\hline
\end{tabular}

(1) LR - Latossolo Roxo, R - Solo Litólico e V - Vertissolo. ${ }^{(2)}$ Na literatura, os valores do parâmetro $K$ de Langmuir são dados em L.mg ${ }^{-1}$ ou $\left(m g \cdot L^{-1}\right)^{-1} \cdot r^{2}-$ coeficiente de correlação linear.

Tabela 4. Matriz de correlação linear entre os parâmetros das isotermas de Langmuir, Freundlich e Temkin com algumas características dos solos estudados.

\begin{tabular}{lcccccc}
\hline Características dos solos & \multicolumn{2}{c}{ Langmuir } & \multicolumn{2}{c}{ Freundlich } & \multicolumn{2}{c}{ Temkin } \\
\hline & $b$ & $K$ & $k f$ & $n$ & $B$ & $-0,104 \mathrm{~ns}$ \\
\hline Matéria orgânica & $-0,043 \mathrm{~ns}$ & $-0,490 \mathrm{~ns}$ & $-0,364 \mathrm{~ns}$ & $0,358 \mathrm{~ns}$ & $-0,145 \mathrm{~ns}$ & $0,998^{* *}$ \\
$\mathrm{CTC}$ & $0,993^{* *}$ & $0,937 \mathrm{~ns}$ & $0,976 \mathrm{~ns}$ & $0,977 \mathrm{~ns}$ & $0,999^{* *}$ & $1,000^{* *}$ \\
$\mathrm{ASE}$ & $0,998^{*}$ & $0,916 \mathrm{~ns}$ & $0,963 \mathrm{~ns}$ & $-0,965 \mathrm{~ns}$ & $0,999^{* *}$ & $-0,926 \mathrm{~ns}$ \\
$\mathrm{Fe}_{2} \mathrm{O}_{3}$ & $-0,902 \mathrm{~ns}$ & $-0,999^{* *}$ & $-0,993^{*}$ & $0,992^{*}$ & $-0,941 \mathrm{~ns}$ & $-0,970 \mathrm{~ns}$ \\
$\mathrm{Gibbsita}_{\text {Caulinita }}$ & $-0,954 \mathrm{~ns}$ & $-0,986 \mathrm{~ns}$ & $-0,999^{* *}$ & $0,999^{*}$ & $-0,980 \mathrm{~ns}$ & $0,913 \mathrm{~ns}$ \\
Argilas 2:1 & $-0,840 \mathrm{~ns}$ & $0,994^{*}$ & $-0,970 \mathrm{~ns}$ & $0,969 \mathrm{~ns}$ & $-0,891 \mathrm{~ns}$ & $-0,872 \mathrm{~ns}$ \\
\hline
\end{tabular}

\footnotetext{
*significativo a $10 \%$; **significativo a $5 \%$; ns não significativo pelo teste $\mathrm{t}$.
} 

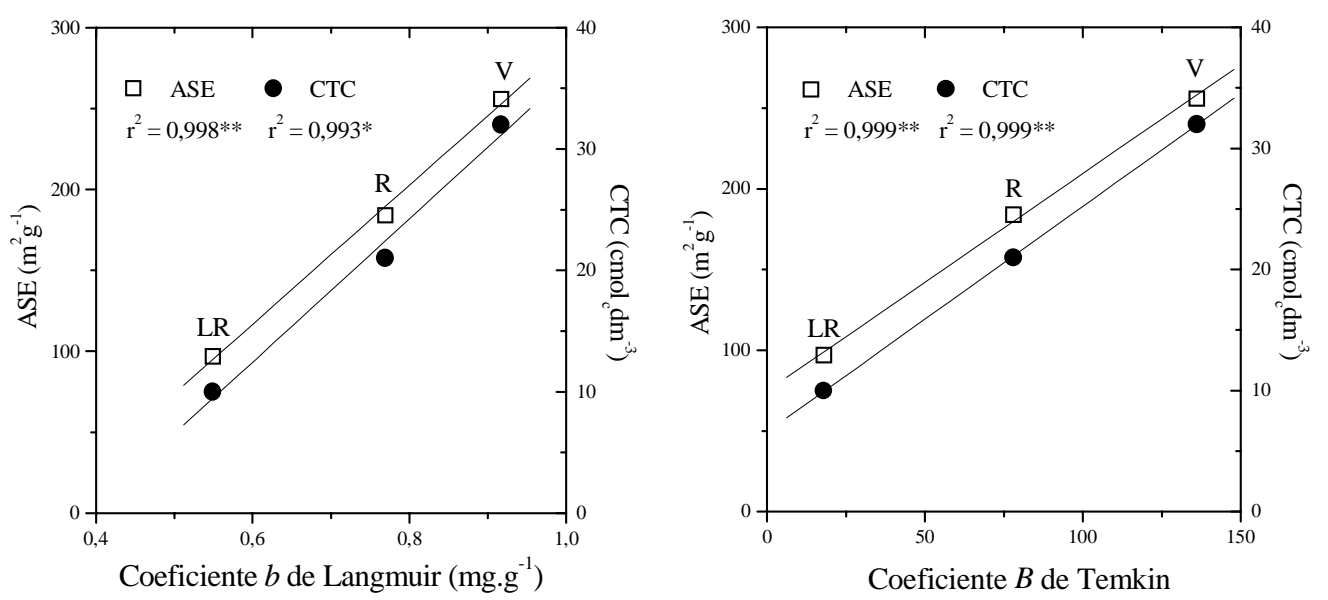

Figura 3. Relações lineares entre CTC e ASE total com a capacidade adsortiva de cobre dos solos estudados determinadas pelo parâmetro b de Langmuir (CMACu) e pelo parâmetro B de Temkin. LR - Latossolo Roxo, $R$ - Solo Litólico e V - Vertissolo.

tivos para tal variável, mesmo apresentando correlações lineares relativamente boas $(0,880$ e 0,929 , respectivamente). Isto ocorre devido à pequena quantidade de solos utilizados nesta análise, que reduz a variabilidade dos resultados.

Na figura 3 os parâmetros $b$ de Langmuir e $B$ de Temkin, relacionados com a capacidade adsortiva dos solos, mostram uma alta correlação com a área superficial específica total (ASE) e a capacidade de troca catiônica (CTC) dos solos estudados (Tabela 4). A linearidade das curvas indica que tanto a CTC como a ASE podem ser utilizadas como parâmetros para separar grupos de solos com baixos teores de matéria orgânica em relação à adsorção do cobre.

Foi visto que os coeficientes de correlação linear $\left(\mathrm{r}^{2}\right)$ obtidos através dos três modelos de adsorção estudados mostraram-se altamente significativos (Tabela 3). Entretanto, ao se refazer o gráfico para as concentrações de cobre na solução de equilíbrio $(C)$, a partir das equações lineares encontradas para cada solo sob cada modelo teórico, tem-se um resultado interessante. Neste caso, notou-se uma aproximação maior do modelo de Freundlich para o solo LR (Figura 4).

$\mathrm{O}$ uso da equação de Langmuir para este solo proporcionou uma superestimativa dos valores de cobre na solução de equilíbrio.

O solo LR apresentou a menor capacidade de adsorção (Tabela 3) e, conseqüentemente, maiores concentrações de cobre que permaneceram na solução de equilíbrio, sugerindo assim, melhor representatividade de Langmuir para baixas concentrações. Da mesma forma, observou-se também uma maior correlação do modelo de Langmuir para o solo $\mathrm{V}$ que apresentou a maior capacidade adsortiva. Dados semelhantes foram observados por Jordão e colaboradores ${ }^{31}$ que, dividindo as isotermas em duas porções, obtiveram maiores coeficientes de correlação para a primeira porção da curva, relativa a baixas concentrações do íon na solução de equilíbrio.

O modelo de Temkin ofereceu coeficientes de correlação elevados (Tabela 3 ), pequenas diferenças nos valores de cobre na solução de equilíbrio em comparação aos dados experimentais (Figura 4) e correlações lineares significativas com algumas características dos solos (Tabela 4). Entretanto, estudos de interpretação de resultados a partir deste modelo teórico são quase inexistentes, já que a utilização deste modelo para a descrição da adsorção de outros elementos pelo solo, não se mostrou eficiente ${ }^{34,40}$

Fica demonstrada, então, a necessidade de se desenvolverem mais estudos em relação ao comportamento de espécies químicas em solos, com ênfase na aplicabilidade e interpretação de modelos teóricos de adsorção, estabelecendo um provável relacionamento entre os parâmetros destes modelos com as características físicas, químicas e mineralógicas dos solos.
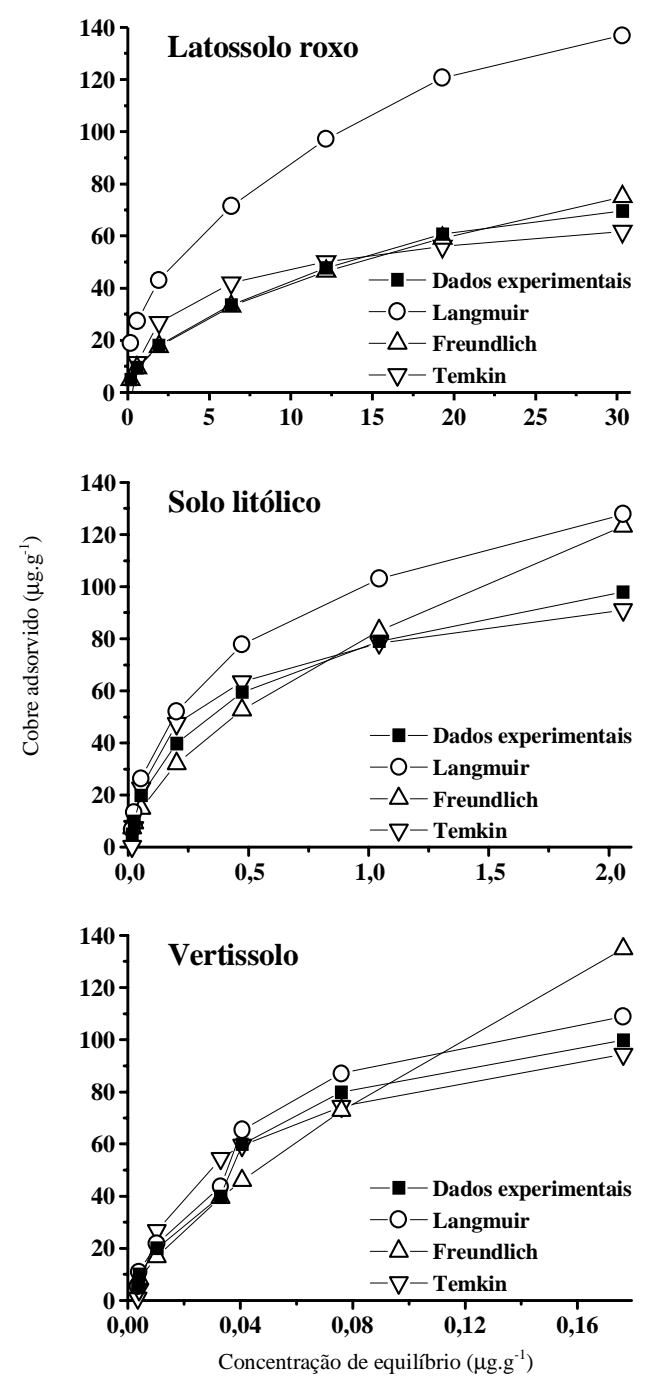

Figura 4. Isotermas obtidas a partir do ajuste das equações de adsorção aos dados obtidos experimentalmente para os valores do cobre na solução de equilíbrio.

Na Tabela 5, são apresentados os dados referentes a otimização da forma linear da isoterma de Langmuir para os solos LR e R, dividindo-se a curva em duas porções ou regiões distintas. Este tipo de análise oferece diferentes parâmetros $b$ e $K$ pelo 
Tabela 5. Parâmetros da otimização dos dados referentes à separação das isotermas de Langmuir em duas regiões nos solos LR e R.

\begin{tabular}{|c|c|c|c|c|c|c|}
\hline \multirow[t]{3}{*}{ Solos $^{(1)}$} & \multicolumn{3}{|c|}{ Capacidade máxima de adsorção do cobre $(b)$} & \multicolumn{3}{|c|}{ "Energia da ligação" $(K)$} \\
\hline & \multicolumn{3}{|c|}{ Regiões } & \multicolumn{3}{|c|}{ Regiões } \\
\hline & Única & I & II & Única & I & II \\
\hline & $m g \cdot g^{-1}$ & & & L. $\mathrm{mg}^{-1}$ & & \\
\hline LR & 0,549 & 0,358 & 0,658 & 0,18 & 0,92 & 0,10 \\
\hline $\mathrm{R}$ & 0,769 & 0,478 & 0,820 & 3,13 & 6,73 & 2,04 \\
\hline
\end{tabular}

(1) LR - Latossolo Roxo e R - Solo Litólico.

ajuste de uma curva independente para cada região. A separação das isotermas foi feita graficamente a partir dos dados plotados. Não foi possível aplicar este tipo de procedimento ao solo $\mathrm{V}$ devido a uma dispersão dos valores de adsorção para as doses iniciais de 5, 10 e $20 \mu \mathrm{g} . \mathrm{g}^{-1}$ de cobre, causada pela elevada concentração original do mesmo presente no solo (Tabela 1).

A diferença observada entre os parâmetros obtidos para cada porção das isotermas, sugere que o cobre possa estar ligado aos sítios energéticos dos colóides do solo sob duas ou mais formas distintas. Para ambos os solos, a região I apresentou elevados valores de $K$ e baixa capacidade máxima de adsorção (b), quando comparadas aos dados observados para a região única (isoterma completa) e para a região II (Tabela 5). Deste modo, acredita-se que na primeira região o solo adsorve uma quantidade relativamente baixa de cobre, mas a energia que o mantém adsorvido pode ser caracterizada pela formação de complexos altamente estáveis. Esta forte atração inicial entre o metal em solução e a fase sólida do solo evidencia ainda mais a formação de uma isoterma do tipo $\mathrm{H}^{12,32}$, devido à alta afinidade entre os componentes orgânicos do solo e o cobre ${ }^{5,14}$. $\mathrm{Na}$ região II, os sítios energéticos responsáveis pela retenção do metal apresentaram os menores parâmetros referentes à energia de ligação $(K)$. Segundo Jordão e colaboradores ${ }^{31}$ este comportamento pode estar relacionado às ligações formadas por interações de caráter eletrostático e, ou forças de van der Walls. Deve-se considerar também, a formação de complexos de esfera interna, isto é, que apresentam ligações de caráter covalente $\left([\mathrm{solo}] \rightarrow \mathrm{Cu}^{(\mathrm{n}-2)-}\right)$ e externa, isto é, que apresentam ligações de caráter eletrovalente $\left([\text { solo }]^{\mathrm{n}-}{ }_{(\mathrm{aq})}{ }^{\cdots} \mathrm{Cu}^{2+}{ }_{(\mathrm{aq})}\right)^{12}$, que ocorrem nas superfícies laterais dos oxo-hidróxidos de ferro e alumínio $^{37}$. Estas ligações de caráter covalente estão presentes em ambas regiões de adsorção, mas na região II, mostram-se menos intensas que na primeira região.

\section{REFERÊNCIAS}

1. Nriagu, J. O.; Pacyna, J.; Nature 1988, 333, 134.

2. Tavares, T. M.; Carvalho, F. M.; Quim. Nova 1992, 15, 147.

3. Alloway, B. J. [Editor]; Heavy Metals in Soils; John Wilwy \& Sons, Inc. New York, 1990.

4. Baird, C.; Environmental Chemistry; W. H. Freeman \& Co.; New York, 1999.

5. McBride, M. B.; Environmental Chemistry of Soils; Oxford University Press; New York, 1994.

6. Kabata-Pendias, A.; Pendias, H.; Trace Elements in Soils and Plants; CRC Press; Boca Raton, 1992.

7. McBride, M. B.; Sauvé, S.; Hendershot, W.; Eur. J. Soil Sci. 1997, 48, 379.

8. Hunt, C. B.; Geology of Soils: Their Evolution, Classification, and Uses. W. H. Freeman \& Co. San Francisco, 1972

9. Atkins, P. W.; Physical Chemistry; Oxford University Press; Oxford, 1994.
10. Schnitzer, M.; Soil Sci. Soc. Am. J. 1969, 33, 75.

11. Hsu, P. H. In Minerals in Soil Environments; Dixon, J.B.; Weed, B., Ed., Book 1; SSSA Madison, 1989.

12. Sposito, G. The Chemistry of Soils; Oxford University Press; New York, 1989.

13. Raij, B.van; Bragantia 1969, 28, 85.

14. Matos, A. T.; Fontes, M. P. F.; Jordão, C. P.; Costa, L. M.; R. Bras. Ci. Solo 1996, 20, 379.

15. Hoog, D. S.; McLaren, R. G.; Swift, R. S.; Soil Sci. Soc. Am. J. 1993, 57, 361.

16. Harter, R. D.; Soil Sci. Soc. Am. J. 1983, 47, 47.

17. Harter, R.; Soil Sci. Soc. Am. J. 1984, 48, 749.

18. Barrow, N. J.; Soil Sci.1978, 29, 447.

19. Costa, A. C. S. da.; Ph.D. Thesis; The Ohio State University, 1996.

20. Embrapa; Manual de Métodos e Análises de Solos. Rio de Janeiro, 1997.

21. Dyal, R. S.; Hendricks, S. B.; Soil Sci. 1950, 69, 421.

22. Embrapa; Manual de Métodos e Análises Químicas de Solos, Plantas e Fertilizantes. Brasília, $1999^{a}$.

23. Iapar; Manual de Análise Química de Solo e Controle de Qualidade. Circular 76, Londrina, 1992.

24. Mehra, O. P.; Jackson, M. L.;. Iron Oxide Removal from Soils by a Dithionite-Citrate System Buffered with Sodium Bicarbonate; Pergamon Press, New York, 1960.

25. Kämpf, N.; Schwertmann, U.; Clays Clay Min. 1982, 30, 401.

26. Karathanasis, A. D.; Hajek, B. F.; Soil Sci. Soc. Am. J. 1983, 47, 158.

27. Böttcher, J.; Eur. J. Soil Sci. 1997, 48, 379.

28. Cavallaro, N.; McBride, M. B.; Soil Sci. Soc. Am. J. 1978, $42,550$.

29. Embrapa; Levantamento de Reconhecimento dos Solos do Estado do Paraná. V. 1 e 2; Londrina, 1984.

30. Schwertmann, U.; Herbillon, A. J. In Myths and Science of Soils of the Tropics; Lal, R.; Sanchez, P. A., Ed., Pub 29; SSSA Madison, 1992.

31. Jordão, C. P.; Alves, M. A.; Pereira, J. L.; Bellato, C. R.; Alvarez, V. H.; Quim. Nova 2000, 23, 5.

32. Sodré, F. F.; Costa, A. C. S.da; Lenzi, E.; Acta Scientiarum 1999, $21,483$.

33. Ker, J. C.; Fontes, M. P. F.; Souza, A. R.; Resende, M.; R. Ceres. 1996, 43, 216.

34. Cunha, R. C. de A.; Camargo, O. A.de; Kinjo, T.; R.. Bras. Ci. Solo 1994, 18, 15.

35. Mondal, A. K.; Mandal, B.; Mandal, L. N.; Commun. Soil Sci. Plant Anal. 1993, 24, 2553.

36. Bohn H. L.; McNeal, B.; O'Connor, G.; Soil Chemistry; John Wiley \& Sons; New York, 1985.

37. McBride, M. B.; Clays Clay Min.1982, 30, 21.

38. Sposito, G.; Soil Sci. Soc. Am. J. 1980, 44, 652.

39. Inskeep, W. P.; Baham, J.; Soil Sci. Soc. Am. J. 1983, $47,660$.

40. Shingh, B. R.; Soil Sci. 1984, 138, 189. 